\title{
Beetle diuretic peptides: The response of mealworm (Tenebrio molitor) Malpighian tubules to synthetic peptides, and cross-reactivity studies with a dung beetle (Onthophagus gazella)
}

\author{
W.D. Holtzhausen ${ }^{a}$ and S.W. Nicolson ${ }^{a}$ \\ ${ }^{\mathrm{a}}$ Department of Zoology and Entomology, University of Pretoria, Pretoria 0002, South \\ Africa
}

\section{Abstract}

This paper reports the effects of different diuretic factors on the Malpighian tubules of beetles. Calcitonin (CT)-like peptides from silkmoth and mosquito increase fluid secretion in a dose-dependent manner in the tubules of Tenebrio molitor, but the cockroach CT-like peptide, Dippu- $\mathrm{DH}_{31}$, has no effect. Thapsigargin induces a small but significant increase in tubule secretion rates. The interactions between different factors in mealworm tubules were explored by testing CT-like peptides, thapsigargin and the mealworm CRF-related diuretic factor Tenmo- $\mathrm{DH}_{37}$ in various combinations, but no synergistic effects were observed. C-terminal fragments of the CRF-related diuretic peptides Locmi- $\mathrm{DH}_{46}$ and Dippu- $\mathrm{DH}_{46}$ fail to increase fluid secretion in mealworm tubules, unlike their corresponding whole peptides. Cross-reactivity of factors between beetle species was investigated using the scarabaeid Onthophagus gazella. Tenmo- $\mathrm{DH}_{37}$ increases fluid secretion in isolated tubules of O. gazella in a dose-dependent manner, revealing a high degree of cross-reactivity in this distantly related beetle species. However, homogenates of $O$. gazella brains inhibited fluid secretion in mealworm tubules. 


\section{Article Outline}

1. Introduction

2. Materials and methods

2.1. Experimental animals

2.2. Fluid secretion assays

2.3. Chemicals

2.4. Statistics

3. Results

3.1. The response of T. molitor tubules to CT-like peptides and thapsigargin

3.2. Interaction between Tenmo- $\mathrm{DH}_{37}$, thapsigargin and CT-like peptides

3.3. Effects on fluid secretion rates of C-terminal fragments of CRF-related and CT-like peptides and corresponding whole peptides

3.4. The response of O. gazella tubules to cyclic AMP and the mealworm peptide Tenmo- $\mathrm{DH}_{37}$

3.5. Effect of O. gazella brain homogenate on mealworm tubules

4. Discussion

4.1. Effects of CT-like peptides and thapsigargin on mealworm tubules and lack of synergism between diuretic factors

4.2. Lack of response of T. molitor tubules to $\mathrm{C}$-terminal fragments of diuretic factors 4.3. Cross-reactivity between beetle species: Effects of diuretic factors and brain homogenates

Acknowledgements

References

\section{Introduction}

Insect water balance is under the control of diuretic and antidiuretic hormones, comprehensively reviewed by Coast et al. (2002). Despite being the largest and most diverse insect order, the Coleoptera have been relatively neglected in studies of neuroendocrine control of Malpighian tubule function. Nicolson and Hanrahan (1986) demonstrated the presence of potent diuretic activity in the Namib Desert tenebrionid 
beetle, Onymacris plana, when they tested homogenates of brain and corpora cardiaca (CC) on isolated tubules. The remarkable stimulation of secretion rates was surprising considering the arid environment that this species inhabits and hence its need to conserve water. In vivo experiments demonstrated that the fluid secreted by the tubules is directed to the midgut for recycling to the haemolymph (Nicolson, 1991). In this way, metabolic wastes are rapidly cleared from the haemolymph without associated loss of water, indicating that diuretic hormones may not always lead to diuresis per se.

Another tenebrionid, the mealworm Tenebrio molitor, is unique in being the only insect from which both diuretic and antidiuretic hormones (acting directly on tubules) have been isolated. The two diuretic peptides, Tenmo- $\mathrm{DH}_{37}$ and Tenmo- $\mathrm{DH}_{47}$ (named according to the number of amino acid residues in their structure) both belong to the family of corticotropin releasing factor (CRF)-related peptides, which elicit their response via the second messenger cyclic AMP (Furuya et al., 1995 and Furuya et al., 1998). Tenmo- $\mathrm{DH}_{37}$ is the more potent of the two, with $\mathrm{EC}_{50}$ values in the nanomolar range (Wiehart et al., 2002a). This peptide has been immunocytochemically localised in the brain, CC, abdominal ganglia and posterior midgut of T. molitor (Wiehart et al., 2002b), further evidence of its physiological function as a diuretic hormone in this insect.

In addition to these two diuretic peptides, the mealworm also possesses two antidiuretic peptides that act directly on Malpighian tubules. Tenmo-ADFa and Tenmo-ADFb both inhibit fluid secretion in mealworm tubules and act via the second messenger cyclic GMP (Eigenheer et al., 2002 and Eigenheer et al., 2003). These two peptides are structurally unrelated to each other and to any other family of insect neuropeptides. In the first known example of antagonistic interactions between endogenous neuropeptides acting on Malpighian tubules, Tenmo-ADFa was shown to reverse the stimulatory effect of Tenmo$\mathrm{DH}_{37}$ on mealworm tubules (Wiehart et al., 2002a).

The main families of insect diuretic hormones are the CRF-related peptides, calcitonin (CT)-like peptides and insect kinins (Coast et al., 2002). CRF-related peptides are the best characterised and, because of their similarity to the CRF-related peptides of vertebrates, are grouped with them in the same superfamily (Coast, 1998). In addition to those of T. molitor, these peptides have been isolated from Blattodea, Isoptera, Orthoptera, Diptera and Lepidoptera, and are suspected to be universal in insects (Coast 
et al., 2002). They act by increasing cyclic AMP production in Malpighian tubules and stimulate cation $\left(\mathrm{K}^{+} / \mathrm{Na}^{+}\right)$transport (reviewed by Nicolson, 1993; Beyenbach, 1995; Coast et al., 2002). They range from 30 to 47 amino acid residues in length, and all have a hydrophobic amide at the C-terminus except the CRF-related peptides from T. molitor, which are of particular interest because they exist as free acids instead (Furuya et al., 1995 and Furuya et al., 1998).

Originally known as the myokinins because of their myotropic activity, the kinins were first isolated from the Madeira cockroach, Leucophaea maderae (Holman et al., 1986). Hayes et al. (1989) were the first to demonstrate their diuretic activity in Malpighian tubules. However, it is uncertain if this is their function in vivo, since they are also effective stimulants of hindgut contraction. Kinins are much smaller than the CRF-related peptides: typically 6-15 residues long (Coast et al., 2002). They appear to have a nonselective effect on ion secretion by opening a $\mathrm{Ca}^{2+}$-activated anion conductance, thus allowing more $\mathrm{Cl}^{-}$into the tubule. With the increase in available $\mathrm{Cl}^{-}$, additional $\mathrm{Na}^{+}$and $\mathrm{K}^{+}$can be transported into the lumen. Kinins are known from Blattodea, Lepidoptera and Diptera, but have not been isolated from Coleoptera to date (Coast et al., 2002). More recently, a peptide was isolated from the cockroach Diploptera punctata that did not correspond to any known insect peptide but did show some similarity to vertebrate CT (Furuya et al., 2000). The D. punctata peptide, subsequently named Dippu- $\mathrm{DH}_{31}$, proved to be the first example of a whole new family of insect diuretic peptides, the CTlike peptides. Dippu-DH $\mathrm{DH}_{31}$ was isolated concurrently with a CRF-related peptide, Dippu$\mathrm{DH}_{46}$, using the same cyclic AMP assay. It is suspected that CT-like peptides target a different cyclic AMP-dependent effector system or activate a different second messenger pathway to that of CRF-related peptides (Coast et al., 2002). The two peptides differ in their modes of action (Dippu- $-\mathrm{DH}_{31}$ has no effect on the $\mathrm{Na}^{+} / \mathrm{K}^{+}$ratio of secreted fluid) and they act synergistically in D. punctata (Furuya et al., 2000). CT-like peptides have since been identified in other orders-Diptera (Coast et al., 2001 and Coast et al., 2005), Lepidoptera (D.A. Schooley, unpublished data) and one has been partially sequenced from Hymenoptera (Laenen, 1999; Coast et al., 2002). A CT-like peptide has yet to be isolated from Coleoptera. 
This study focuses on beetles in further examining the effects and interactions of diuretic peptides on their Malpighian tubules. We have investigated the following: 1. The effect of thapsigargin, which mimics the action of kinins, and CT-like peptides on fluid secretion in tubules of $T$. molitor, exploring the possibility of synergism between different diuretic factors; 2 . Structure/activity relationships, by testing C-terminal fragments of diuretic peptides from different species on mealworm tubules; and 3. Crossreactivity between beetle species, by examining the effects of Tenmo- $\mathrm{DH}_{37}$ on the tubules of a distantly related beetle species, the dung beetle Onthophagus gazella (Scarabaeidae).

\section{Materials and methods}

\subsection{Experimental animals}

T. molitor larvae were maintained at room temperature in dry bran. Apple or potato slices were provided on a regular basis as a source of moisture. Care was taken to select mealworms of similar size for experiments. O. gazella were collected near Bronkhorstspruit, east of Pretoria, maintained in buckets containing soil and fed fresh cow dung every 4-6 days. Adult dung beetles were used because larvae and pupae develop in brood balls, making it difficult to determine their stage of development. All experiments were conducted at room temperature $\left(20-24{ }^{\circ} \mathrm{C}\right)$.

\subsection{Fluid secretion assays}

Mealworms were opened dorsally and their tubules dissected out under Ringer's solution (see below). Tubules were dissected only from feeding mealworms that had bran in the midgut. The length of each tubule in the saline droplet varied, but Nicolson (1992) showed that there is no difference in secretion rates between the different regions of mealworm tubules. The arrangement of tubules of O. gazella adults differs from that of larval and adult mealworms: the four very long transparent tubules seem to be more robust than the shorter, pigmented tubules of the mealworm, and the dung beetle does not possess a rectal complex.

Isolated tubules were transferred to $50 \mu 1$ droplets of Ringer's solution beneath liquid paraffin in a Sylgard-covered Petri dish. The Ringer used for isolated tubules had the following composition in $\mathrm{mM}: \mathrm{NaCl}, 90 ; \mathrm{KCl}, 50 ; \mathrm{MgCl}_{2}, 5 ; \mathrm{CaCl}_{2} 2 ; \mathrm{NaHCO}_{3}, 6$; 
$\mathrm{NaH}_{2} \mathrm{PO}_{4}$, 4; glucose, 50; glycine, 10; proline, 10; serine, 10; histidine, 10; and glutamine, 10 (Nicolson, 1992). The $\mathrm{pH}$ was adjusted to 7.0 with $\mathrm{NaOH}$, and phenol red was used as an indicator. Two tubules were placed in each droplet and both ends were drawn out of the saline into the paraffin and wrapped around minuten pins. Because of the absence of a rectal complex in O. gazella the tubules are blind ending, but the portions of whole tubules used were severed at both ends. The length of each tubule in the Ringer varied, but each tubule served as its own control.

Tubules were allowed approximately $20 \mathrm{~min}$ to equilibrate before control measurements were made. They usually secreted at one end only, and the secreted droplets were collected and transferred to the Sylgard-covered base with a fine glass pipette. The diameter of each droplet was measured using a calibrated eyepiece graticule and the volume (nl) and rate of secretion ( $\mathrm{nl} / \mathrm{min}$ ) were calculated assuming the droplet to be spherical. After 2-3 control measurements at 10-15 min intervals, the bathing Ringer was replaced with $50 \mu \mathrm{l}$ of Ringer containing the test substance. Measurements of secreted droplets were again taken at 10-15 min intervals to calculate the rate of secretion in the presence of the test substance. In experiments testing substances in combination, a third step was included, in which the initial test substance was removed and replaced with saline containing 2 test substances. At the end of each experiment, $0.1 \mathrm{mM}$ dibutyryl cyclic AMP (db-cyclic AMP) was added to stimulate maximal rates of secretion and for dose-response curves results were expressed as a percentage of the maximum. Unless otherwise stated, this protocol was used for all experiments.

Dibutyryl cyclic AMP was tested on O. gazella tubules in the presence of 3-isobutyl-1methylxanthine (IBMX), an inhibitor of cyclic AMP phosphodiesterase activity. IBMX was dissolved in dimethylsulphoxide (DMSO), and stored as a stock solution (250 mM). The desired concentration was obtained by further dilution in Ringer's solution to obtain $0.5 \mathrm{mM}$ IBMX and $\leqslant 0.2 \%$ DMSO in the final working solution.

For preparation of tissue homogenates, mealworms and dung beetles were decapitated (dung beetle heads were stored at $-20^{\circ} \mathrm{C}$ until use). For both species, brains (with $\mathrm{CC}$ included) were dissected out under Ringer's solution and transferred to a small glass mortar with a drop of Ringer. The tissue was ground up with a glass rod and the homogenate was added to Ringer to give a concentration of $1 \mathrm{brain} / 100 \mu \mathrm{l}$. 


\subsection{Chemicals}

No kinins have yet been isolated from Coleoptera, but thapsigargin can be used as a substitute for kinins as it is a specific inhibitor of $\mathrm{Ca}^{2+}$ uptake by intracellular stores, thereby increasing intracellular $\mathrm{Ca}^{2+}$ (Thastrup et al., 1990; Yu and Beyenbach, 2002). Thapsigargin was dissolved in DMSO and diluted in Ringer's solution to $1 \mu \mathrm{M}$ (the final concentration of DMSO was $0.1 \%$ ). Synthetic peptides (CRF-related peptides Tenmo$\mathrm{DH}_{37}$, Locmi-DH$_{46}$, Dippu-DH ${ }_{46}$, and CT-like peptides Bommo-DH ${ }_{31}$, Dippu-DH ${ }_{31}$ and Anoga- $\mathrm{DH}_{31}$ ) were gifts from David Schooley (University of Nevada, Reno, USA). The truncated peptide analogues Locmi-DH ${ }_{32-46}$, Dippu-DH $\mathrm{DH}_{32-46}$ and Dippu- $\mathrm{DH}_{17-31}$ were synthesised by Charoula Kaskani and Constantine Poulos (Department of Chemistry, University of Patras, Patras, Greece). Peptides were dissolved in 60\% acetonitrile, in order to minimise adherence to the sides of polypropylene containers. Ringer's solution was used to dilute to the desired concentration, with $\leqslant 0.6 \%$ acetonitrile in the final working solution (at this concentration, acetonitrile does not affect secretion rates in mealworm tubules; S.W. Nicolson, unpublished data). All other chemicals were purchased from Sigma.

\subsection{Statistics}

Results are presented as the means \pm standard error (SE). Each tubule segment served as its own control. Statistical differences were calculated using the paired Student's $t$-test, or one-way ANOVA followed by Tukey's Honest Significant Difference test, with $P<0.05$ accepted as significant. GraphPad Prism 4.0 was used to fit dose-response curves (nonlinear regression).

\section{Results}

\subsection{The response of $T$. molitor tubules to CT-like peptides and thapsigargin}

The CT-like peptides Dippu- $\mathrm{DH}_{31}$, Bommo- $\mathrm{DH}_{31}$ and Anoga- $\mathrm{DH}_{31}$ (from the cockroach Periplaneta americana, the silkmoth Bombyx mori and the malaria mosquito Anopheles gambiae, respectively) were tested for diuretic activity on isolated mealworm tubules. Both Bommo- $\mathrm{DH}_{31}$ and Anoga- $\mathrm{DH}_{31}$ stimulated fluid secretion in T. molitor tubules in a dose-dependent manner (Fig. 1), with $\mathrm{EC}_{50}$ values of 0.61 and $14 \mathrm{nM}$ respectively (95\% 
confidence limits: $0.2-1.8 \mathrm{nM}$ for Bommo- $\mathrm{DH}_{31}$ and $0.63-320 \mathrm{nM}$ for Anoga- $\left.\mathrm{DH}_{31}\right)$. The highest concentration used was $1 \mu \mathrm{M}$ and for both peptides the response was approximately $50 \%$ of maximum stimulation due to $0.1 \mathrm{mM}$ db-cyclic AMP. However, at a concentration of $1 \mu \mathrm{M}$, the cockroach CT-like peptide Dippu- $\mathrm{DH}_{31}$ failed to stimulate mealworm tubule secretion (see Fig. 4).

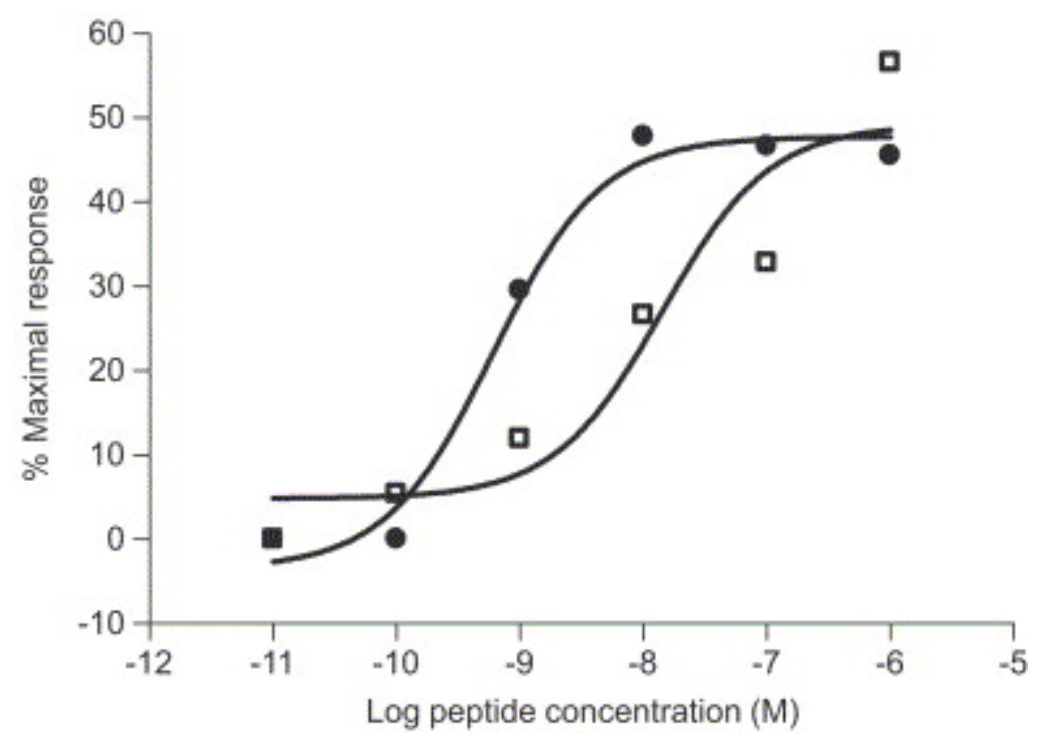

Fig. 1. Dose-response curves for the effect of Bombyx mori and Anopheles gambiae calcitonin-like peptides on fluid secretion in Tenebrio tubules. Data points are the means of 7-10 determinations for Bommo- $\mathrm{DH}_{31}$ (filled circles) and 6-8 determinations for Anoga- $\mathrm{DH}_{31}$ (open squares), and results are expressed as the percentage of the maximum response obtained in the presence of $0.1 \mathrm{mM}$ dibutyryl cyclic AMP. The $\mathrm{EC}_{50}$ values are $0.61 \mathrm{nM}$ for Bommo- $\mathrm{DH}_{31}$ and $14 \mathrm{nM}$ for Anoga- $\mathrm{DH}_{31}\left(r^{2}\right.$ values for the curve fits are 0.99 and 0.89 , respectively). Standard errors of the mean are very small and so are not visible.

The increase in secretion rates in mealworm tubules effected by $1 \mu \mathrm{M}$ thapsigargin was $22.5 \%$ of the maximum response to $0.1 \mathrm{mM} \mathrm{db}$-cyclic AMP (Fig. 2). The increase is significant $(P<0.001)$ but very small relative to that caused by cyclic AMP. 


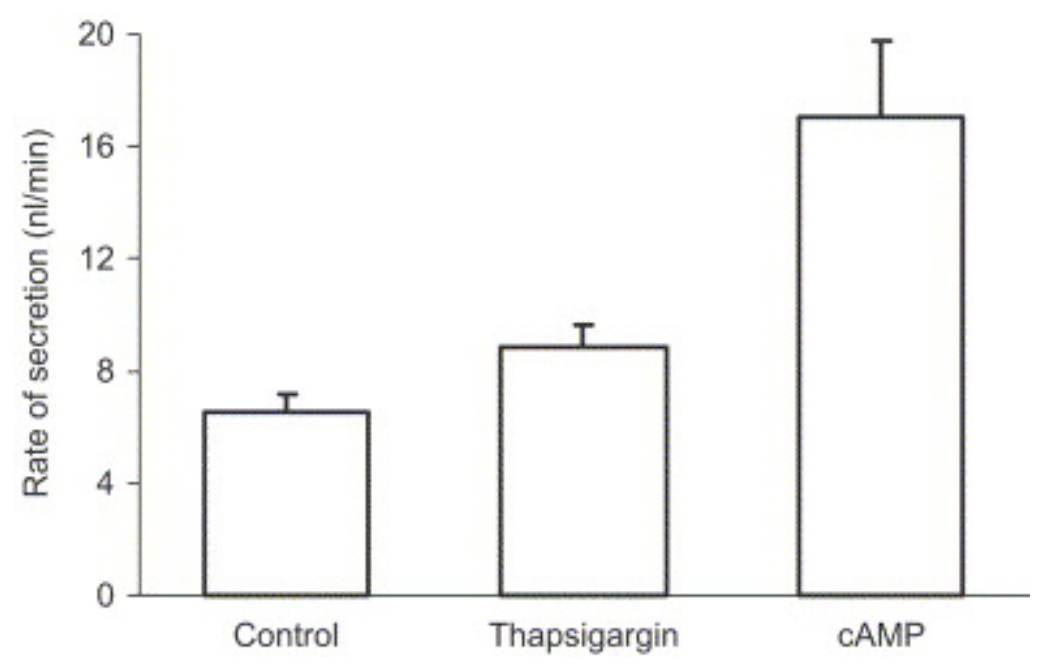

Fig. 2. The effect of thapsigargin, a pharmacological agent that mimics the effects of kinins, on Tenebrio tubules. At a concentration of $1 \mu \mathrm{M}$, thapsigargin increases fluid secretion to $22.5 \%$ of the maximal response to $0.1 \mathrm{mM} \mathrm{db}$-cyclic AMP. The increase is not significant $(P>0.05)$. Bars represent the mean for 7 tubules and vertical lines are SEs.

\subsection{Interaction between Tenmo- $\mathrm{DH}_{37}$, thapsigargin and $\mathrm{CT}$-like peptides}

We first measured the response of isolated tubules to $1 \mathrm{nM}$ Tenmo- $\mathrm{DH}_{37}$, approximately ten times the $\mathrm{EC}_{50}$ for this peptide (Wiehart et al., 2002a), followed by the response to $1 \mathrm{nM}$ Tenmo- $\mathrm{DH}_{37}$ together with $1 \mu \mathrm{M}$ thapsigargin. The results are shown in Fig. 3(a). Secretion rates increased in the presence of Tenmo- $\mathrm{DH}_{37}$ alone, but when tested in combination with thapsigargin, no further significant increase was observed $(P>0.05)$. 

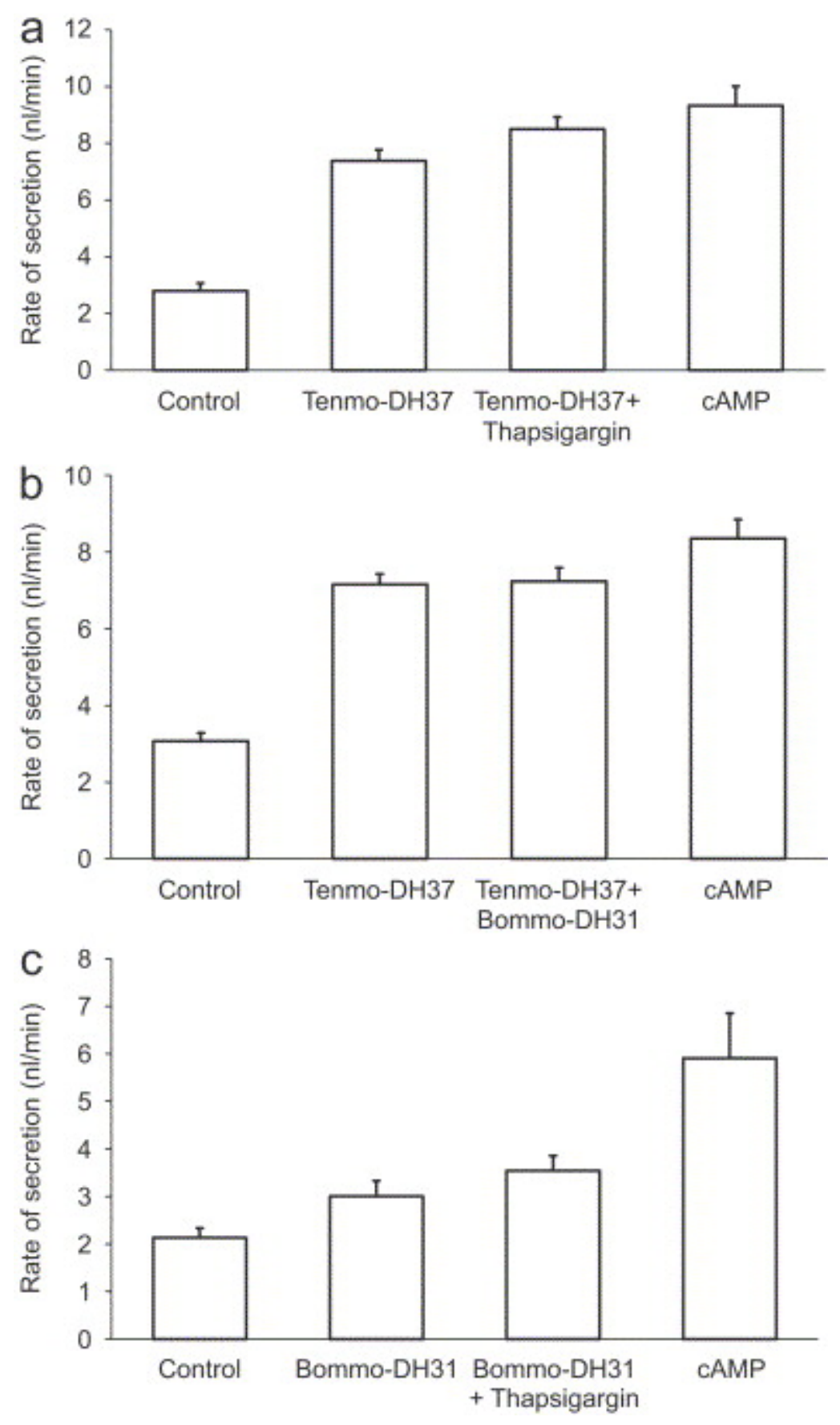

Fig. 3. (a)-(c) No synergistic or additive effects were observed between (a) a CRF-related peptide and thapsigargin, (b) a calcitonin-like peptide and a CRF-related peptide, or (c) a calcitonin-like peptide and thapsigargin in Tenebrio tubules. Bars represent the means and vertical lines the SEs. (a) No significant increase occurs with the addition of $1 \mu \mathrm{M}$ thapsigargin to $1 \mathrm{nM}$ Tenmo- $\mathrm{DH}_{37}(P>0.05 ; n=11)$. (b) At $10 \mathrm{nM}$, the CRF-related 
Tenmo- $\mathrm{DH}_{37}$ alone increases secretion to approximately $80 \%$ of maximum, but no further increase occurs with the addition of $1 \mu \mathrm{M}$ Bommo- $\mathrm{DH}_{31}(P>0.05 ; n=7)$. (c) No significant increase in fluid secretion rates takes place in the presence of $1 \mathrm{nM}$ Bommo$\mathrm{DH}_{31}$ and $1 \mu \mathrm{M}$ thapsigargin combined $(P>0.3 ; n=6)$.

Next, we tested the effects on beetle tubules of combining a CRF-related peptide (Tenmo- $\mathrm{DH}_{37}$ ) with a CT-like peptide (Bommo- $\mathrm{DH}_{31}$ ). Tubules were first exposed to $1 \mathrm{nM}$ Tenmo- $\mathrm{DH}_{37}$ and then to $1 \mathrm{nM}$ Tenmo- $\mathrm{DH}_{37}$ together with $1 \mathrm{nM}$ Bommo- $\mathrm{DH}_{31}$ (approximately 1.5 times the $\mathrm{EC}_{50}$ value determined for this peptide in the mealworm), with no further increase in secretion (results not shown). Another experiment was conducted with $10 \mathrm{nM}$ Tenmo- $\mathrm{DH}_{37}$ in combination with $1 \mu \mathrm{M}$ Bommo- $\mathrm{DH}_{31}$ but no significant increase occurred (shown in Fig. 3(b)). The experiment was repeated at other concentrations (10 $\mathrm{nM}$ each) and the order of the peptides was reversed, Bommo- $\mathrm{DH}_{31}$ being tested first, followed by Bommo- $\mathrm{DH}_{31}$ in combination with Tenmo- $\mathrm{DH}_{37}$, but no synergistic or additive effects were observed.

We also investigated interactions between CT-like peptides and thapsigargin in beetle tubules. Secretion rates increased in the presence of $1 \mathrm{nM}$ Bommo- $\mathrm{DH}_{31}$, but there was no further significant increase in the presence of both $1 \mathrm{nM}$ Bommo- $\mathrm{DH}_{31}$ and $1 \mu \mathrm{M}$ thapsigargin $(P>0.05)$ (Fig. 3(c)).

\subsection{Effects on fluid secretion rates of C-terminal fragments of CRF-related and CT- like peptides and corresponding whole peptides}

C-terminal fragments of diuretic peptides were used to examine the structural requirements for stimulation of fluid secretion in Malpighian tubules of Tenebrio. Truncated analogues of the CRF-related peptides Locmi-DH 46 and Dippu-DH ${ }_{46}$ (Locmi$\mathrm{DH}_{32-46}$ and Dippu-DH $\mathrm{DH}_{32-46}$, respectively) and the CT-like peptide Dippu-DH ${ }_{31}$ (Dippu$\mathrm{DH}_{17-31}$ ) were tested for their effects on fluid secretion in mealworm tubules. They were initially tested at $1 \mu \mathrm{M}$ (results not shown), but even at a concentration of $0.1 \mathrm{mM}$, there was no stimulation (Fig. 4). Because these peptides had not previously been tested as whole peptides in T. molitor, complete sequences were tested as well. The two CRFrelated peptides Locmi- $\mathrm{DH}_{46}$ and Dippu-DH ${ }_{46}$ both significantly increased fluid secretion in mealworm tubules at a concentration of $1 \mu \mathrm{M}$ (Fig. 4). Surprisingly, Dippu-DH ${ }_{31}$ did 
not $(P>0.05)$, in contrast to the other CT-like peptides Bommo- $\mathrm{DH}_{31}$ and $A$ noga- $\mathrm{DH}_{31}$ (Fig. 1).

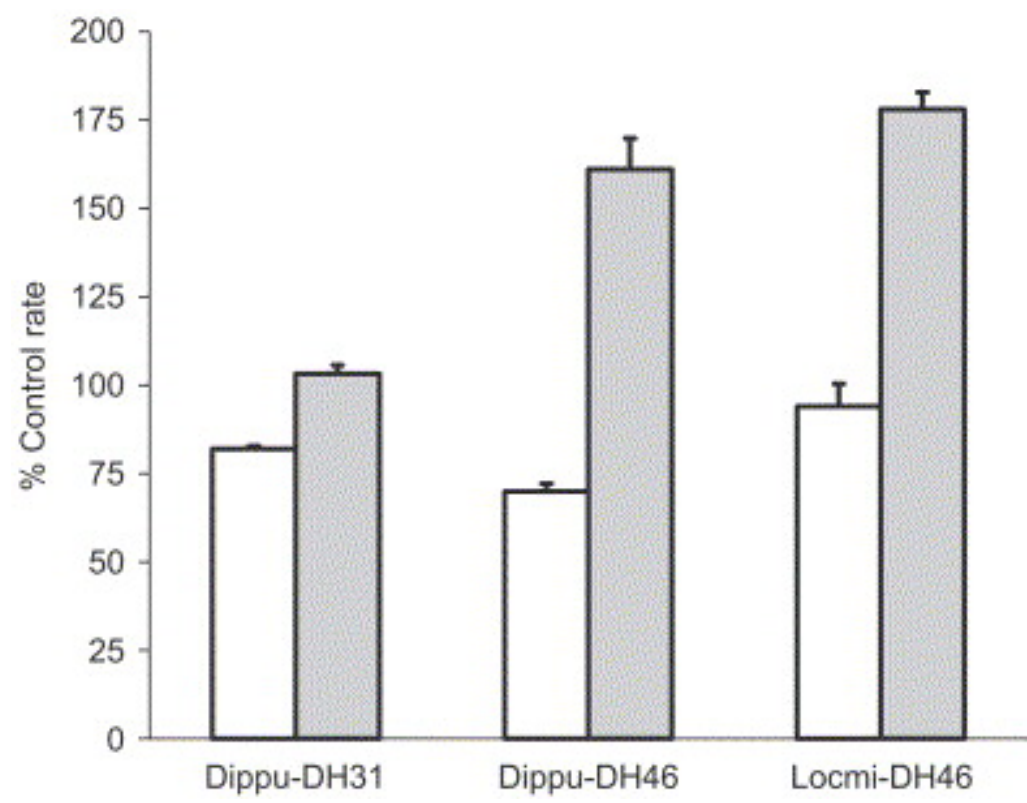

Fig. 4. Comparison of the effects of the C-terminal fragments and corresponding whole peptides of the calcitonin-like peptide Dippu- $\mathrm{DH}_{31}$ and the CRF-related peptides Dippu$\mathrm{DH}_{46}$ and Locmi-DH 46 on fluid secretion in Tenebrio Malpighian tubules. Truncated analogues (open bars) were tested at $0.1 \mathrm{mM}$ and whole peptides (filled bars) at $1 \mu \mathrm{M}$. A value equal to or less than $100 \%$ indicates no increase over control rates $(n=5-6)$. A decrease can be explained by the normal decline in basal secretion rates over time. Dibutyryl cAMP $(0.1 \mathrm{mM})$ was used to stimulate maximum secretion and to ensure that the tubules were still viable (not shown). The calcitonin-like peptide Dippu- $\mathrm{DH}_{31}$ did not stimulate secretion $(P>0.05 ; n=9)$. The CRF-related peptides Dippu-DH ${ }_{46}$ and Locmi-DH both significantly increased fluid secretion rates $(P<0.001$ for both; $n=7-10)$. Vertical bars are SEs.

\subsection{The response of $O$. gazella tubules to cyclic AMP and the mealworm peptide Tenmo-DH 37}

Cyclic AMP appears to be universally involved in fluid secretion by Malpighian tubules. Therefore, before testing other peptides on the tubules of the dung beetle O. gazella, we first explored the effects of exogenous cyclic AMP in this previously unstudied insect. 
Preliminary studies used the sodium salt of cyclic AMP and the apparent lack of response (results not shown) prompted the use of the more membrane permeant analogue db-cyclic AMP. Dibutyryl cyclic AMP was dissolved in DMSO to obtain a working solution of $0.2 \%$, which has previously been shown to have no effect on tubule secretion (Coast, 1995). Similarly, in this study, there was no change in secretion rates when saline was replaced with saline containing $0.2 \%$ DMSO (results not shown). A concentration of $0.1 \mathrm{mM} \mathrm{db}$-cyclic AMP resulted in a significant increase in the fluid secretion rate $(P<0.001)$, shown in Fig. 5 .

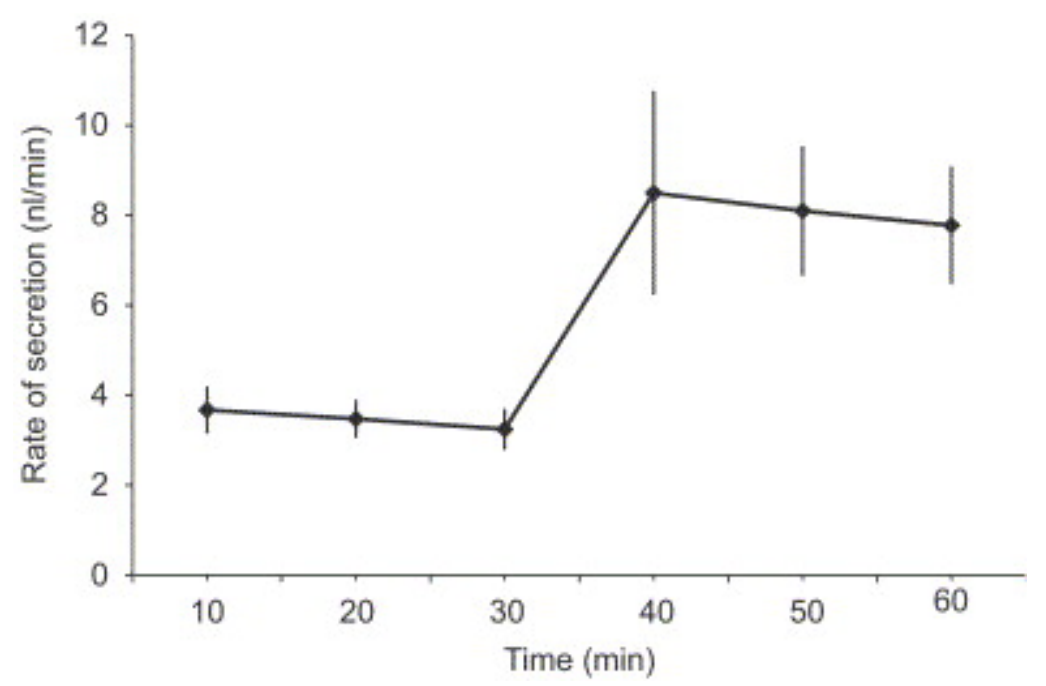

Fig. 5. Dibutyryl cyclic AMP increases fluid secretion in Malpighian tubules of the scarabaeid Onthophagus gazella $(P<0.001 ; n=11)$. cAMP $(0.1 \mathrm{mM})$ was added at time $=30 \mathrm{~min}$.

Tenmo- $\mathrm{DH}_{37}$ stimulated fluid secretion in O. gazella tubules in a dose-dependent manner with an $\mathrm{EC}_{50}$ value of $0.38 \mathrm{nM}$ (Fig. 6). Maximal stimulation by Tenmo- $\mathrm{DH}_{37}$ was obtained at a concentration of $1 \mu \mathrm{M}(68.5 \%$ of the maximal response obtained in the presence of $0.1 \mathrm{mM}$ db-cyclic AMP). 


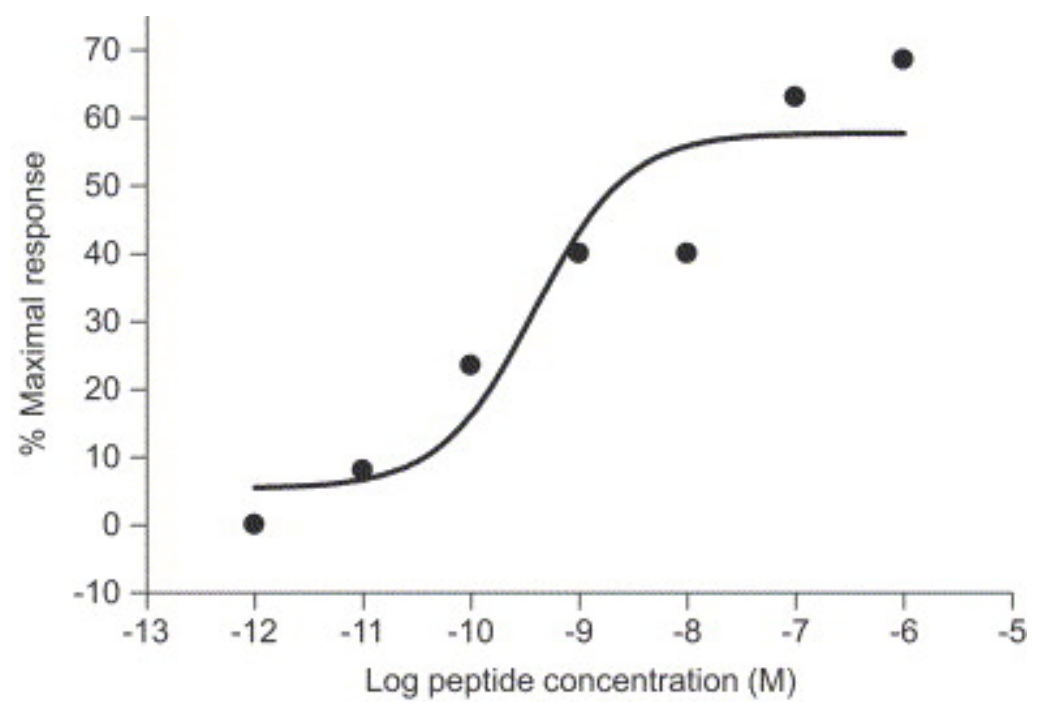

Fig. 6. Dose-response curve for the effect of the mealworm CRF-related diuretic factor Tenmo- $\mathrm{DH}_{37}$ on the tubules of Onthophagus gazella. Data points are means of 5-9 determinations, SEs are too small to see. Results are expressed as a percentage of the maximal response to $0.1 \mathrm{mM}$ dibutyryl cAMP. $\mathrm{EC}_{50}=0.38 \mathrm{nM}\left(r^{2}\right.$ value for the curve fit=0.89).

\subsection{Effect of $O$. gazella brain homogenate on mealworm tubules}

At a concentration of 1 brain/100 $\mu$, the brain homogenate of the dung beetle has an antidiuretic effect in mealworm tubules (Fig. 7). Secretion rates decreased by $66 \%$ $(P<0.005)$, but increased rapidly when the Ringer containing the homogenate was replaced with Ringer containing $0.1 \mathrm{mM}$ db-cyclic AMP. In contrast, homogenates of mealworm brain had a marked stimulatory effect on mealworm tubules $(P<0.001)$ (Fig. 7). 


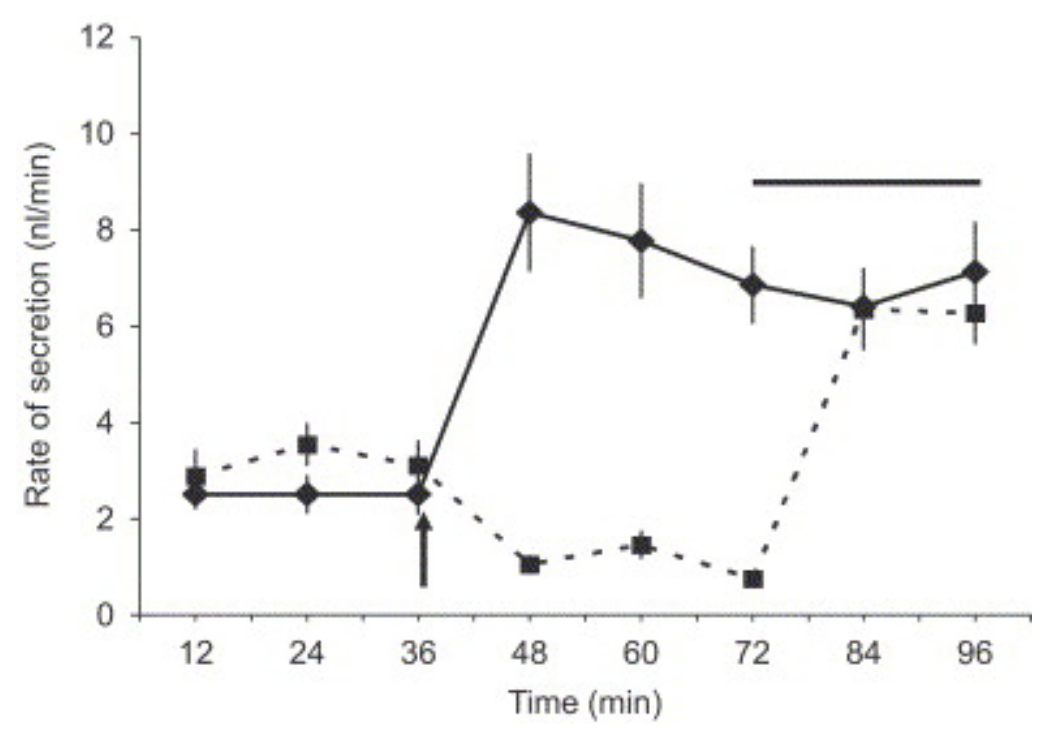

Fig. 7. Secretory response of isolated mealworm tubules to O. gazella brain extract (dashed line) compared to the response to Tenebrio extract (solid line). Arrow shows time of addition of the brain homogenates ( 1 brain/100 $\mu \mathrm{l})$ and horizontal solid bar indicates time of exposure to $0.1 \mathrm{mM}$ cAMP. Secretion rates declined significantly in tubules exposed to O. gazella brain extracts $(P<0.005 ; n=5)$ but increased in the presence of mealworm brain extracts $(P<0.001 ; n=6)$. SEs shown by vertical bars.

To further test the inhibitory effect of $O$. gazella brain extracts on mealworm tubules, and to ensure that the decrease was not due to the normal decline of basal secretion rates over time, tubules were first stimulated with $0.1 \mathrm{mM} \mathrm{db}$-cyclic AMP followed by the addition of homogenate (at $1 \mathrm{brain} / 100 \mu \mathrm{l}$ ) in the presence of db-cyclic AMP. Once more, secretion rates dropped significantly (results not shown).

\section{Discussion}

The availability of a wide range of synthetic diuretic factors has enabled us to examine the interacting effects of these different factors on Malpighian tubule secretion. Because both diuretic and antidiuretic peptides acting on Malpighian tubules have been isolated from T. molitor, this species is ideal for further investigation of water and ion regulation in insects in general and beetles in particular. 


\subsection{Effects of CT-like peptides and thapsigargin on mealworm tubules and lack of synergism between diuretic factors}

The tubules of Tenebrio are sensitive to some CT-like peptides, with both Bommo- $\mathrm{DH}_{31}$ and Anoga- $\mathrm{DH}_{31}$ having $\mathrm{EC}_{50}$ values in the nanomolar range. In fact, with an $\mathrm{EC}_{50}$ of $14 \mathrm{nM}$ in Tenebrio, Anoga- $\mathrm{DH}_{31}$ is slightly more potent than in its source A. gambiae, where the $\mathrm{EC}_{50}$ was $50 \mathrm{nM}$ (Coast et al., 2005). However, in the mealworm, the maximum stimulation in the presence of these CT-like peptides is much less than that for CRF-related diuretic hormones; thus even though CT-like peptides are potent at low concentrations, their effect in Tenebrio tubules is not very powerful. The cockroach CTlike peptide Dippu- $\mathrm{DH}_{31}$ failed to stimulate mealworm tubules and attempts to localise a CT-like peptide in Tenebrio nervous tissue using the antiserum to Dippu- $\mathrm{DH}_{31}$ have not been successful (Holtzhausen, 2006). A CT-like peptide has been immunocytochemically localised in the blood-feeding bug Rhodnius prolixus using antiserum to Dippu- $\mathrm{DH}_{31}(\mathrm{Te}$ Brugge et al., 2005). Interestingly, although a CT-like peptide has not yet been isolated from a beetle, one was identified in another tenebrionid during a partial genome sequence of Tribolium castaneum (D.A. Schooley, personal communication). The failure to localise a CT-like peptide in T. molitor could be because CT-like peptides are not present in detectable amounts in the mealworm nervous system.

However, data on CT-like peptides are limited and we still do not know much about their mode of action. The different effects of these peptides across and even within orders should be noted. For example, the cockroach CT-like peptide Dippu- $\mathrm{DH}_{31}$ has a nonselective effect on the $\mathrm{Na}^{+}$and $\mathrm{K}^{+}$ratio in the cockroach (Furuya et al., 2000) while Anoga- $\mathrm{DH}_{31}$, recently shown by Coast et al. (2005) to be the previously uncharacterised natriuretic peptide of mosquitoes (Petzel et al., 1985), markedly increases $\left[\mathrm{Na}^{+}\right]$relative to $\left[\mathrm{K}^{+}\right]$in the mosquito (Coast et al., 2005).

While the increase in secretion rates induced by thapsigargin was significant, when compared to the effect of CRF-like peptides on mealworm tubules and the effect of kinins on tubules from other insects (flies in particular), the effect was not striking. In the housefly Musca domestica, thapsigargin increases secretion rates 4-5 fold. In the dipteran suborder Cyclorrhapha, kinins stimulate maximum secretion (as with thapsigargin, 4-5 times control rates) (Iaboni et al., 1998) and CRF-related and CT-like peptides are less 
effective, while in the Nematocera, CT-like peptides stimulate maximal secretion rates and CRF-related peptides are less effective, as are kinins (Coast et al., 2005). This difference in relative importance of the various factors within the Diptera corresponds to phylogeny and may depend on whether anion transport is rate limiting (Iaboni et al., 1998). Interestingly, in preliminary studies, kinins from other insect orders (leucokinin, achetakinin and muscakinin) failed to induce a response in isolated tubules of T. molitor (Wiehart et al., 2002a). This raises the possibility that kinins do not play a diuretic role in T. molitor, which would be supported by the failure of thapsigargin to further increase secretion rates in the presence of Tenmo- $\mathrm{DH}_{37}$. It remains to be seen whether kinins do in fact exist in T. molitor.

The lack of synergism in mealworm tubules between Tenmo- $\mathrm{DH}_{37}$ and the CT-like peptide Bommo- $\mathrm{DH}_{31}$ was unexpected, considering the different mechanisms by which these diuretic factors are thought to operate (Coast et al., 2002). In the relatively few studies that have investigated synergistic effects between different factors (Table 1), varied responses have been encountered. For instance, kinins and CRF-related peptides are synergistic in the locust (Locmi-K and Locmi-DH 46 ) (Coast, 1995), but not in the cricket (achetakinin-I and the CRF-related Achdo-DH 46 ) (Coast and Kay, 1994). Also, CRF-related and CT-like peptides from D. punctata (Dippu-DH46 and Dippu-DH $\mathrm{DH}_{31}$ ) are synergistic in the cockroach, but have only an additive effect in L. migratoria ( Furuya et al., 2000). In the same way, it is possible that the action of peptides from other insects in mealworm tubules may differ from that of the native peptides.

Table 1.

Studies examining potential synergistic or additive interactions between different diuretic factors acting via different second messenger pathways

\begin{tabular}{|l|l|l|l|l|}
\hline Factor 1 & Factor 2 & Species & Combined effect & Reference \\
\hline \multicolumn{2}{|l|}{ CRF-related + CT-like } & \multicolumn{2}{|l|}{} \\
\hline Dippu-DH 46 & $\begin{array}{l}\text { Dippu- } \\
\mathrm{DH}_{31}\end{array}$ & D. punctata & Synergistic & $\begin{array}{l}\text { Furuya et al. } \\
\mathbf{( 2 0 0 0 )}\end{array}$ \\
\hline Dippu-DH46 & Dippu- & L. & Additive & Furuya et al. \\
\hline
\end{tabular}




\begin{tabular}{|c|c|c|c|c|}
\hline Factor 1 & Factor 2 & Species & Combined effect & Reference \\
\hline & $\mathrm{DH}_{31}$ & migratoria & & $(2000)$ \\
\hline Locmi-DH & $\begin{array}{l}\text { Dippu- } \\
\mathrm{DH}_{31}\end{array}$ & $\begin{array}{l}\text { L. } \\
\text { migratoria }\end{array}$ & Synergistic & $\begin{array}{l}\text { Furuya et al. } \\
(2000)\end{array}$ \\
\hline \multicolumn{5}{|c|}{ CRF-related+kinin } \\
\hline Locmi-DH & Locmi-K & $\begin{array}{l}\text { L. } \\
\text { migratoria }\end{array}$ & Synergistic & Coast (1995) \\
\hline Musdo-DP & Musdo-K & $\begin{array}{l}\text { M. } \\
\text { domestica }\end{array}$ & Synergistic & $\begin{array}{l}\text { Holman et al. } \\
\text { (1999) }\end{array}$ \\
\hline Achdo-DP & Achdo-K & $\begin{array}{l}\text { A. } \\
\text { domesticus }\end{array}$ & $\begin{array}{l}\text { Not synergistic or } \\
\text { additive }\end{array}$ & $\begin{array}{l}\text { Coast and Kay } \\
\text { (1994) }\end{array}$ \\
\hline \multicolumn{5}{|l|}{ Kinin $+C T$-like } \\
\hline Musdo-K & $\begin{array}{l}\text { Anoga- } \\
\mathrm{DH}_{31}\end{array}$ & An. gambiae & Synergistic & Coast et al. (2005) \\
\hline Locmi-K & $\begin{array}{l}\text { Dippu- } \\
\mathrm{DH}_{31}\end{array}$ & $\begin{array}{l}\text { L. } \\
\text { migratoria }\end{array}$ & Synergistic & $\begin{array}{l}\text { Furuya et al. } \\
\text { (2000) }\end{array}$ \\
\hline Thapsigargin & $\begin{array}{l}\text { Dippu- } \\
\mathrm{DH}_{31}\end{array}$ & $\begin{array}{l}\text { L. } \\
\text { migratoria }\end{array}$ & Additive & $\begin{array}{l}\text { Furuya et al. } \\
\text { (2000) }\end{array}$ \\
\hline
\end{tabular}

Considering the anomaly of a xeric insect such as the mealworm producing at least two potent diuretic factors, it might be presumed that diuresis needs to be controlled precisely in this species. Low concentrations of diuretic factors circulating in the haemolymph would be easier to control, so synergism, which would steepen the dose-response curves and result in a lower concentration necessary for a response (Coast, 1995), would be advantageous. However, while synergism is a plausible explanation for the presence of more than one diuretic factor in the same insect, diuretic peptides may have multiple 
actions or control other physiological processes (Coast et al., 2002). Importantly, different factors that similarly stimulate fluid secretion may have very different effects on ion transport.

\subsection{Lack of response of $T$. molitor tubules to C-terminal fragments of diuretic factors}

Studies using deletion analogues of insect neuropeptides have been carried out to investigate the region of the peptide that binds to and/or activates the relevant receptors. Structure/activity studies in other insects have shown that, for CRF-related peptides, the region towards the $\mathrm{N}$-terminus is important for receptor activation while the $\mathrm{C}$-terminal end is required for receptor binding. For instance, C-terminal fragments of Manse- $\mathrm{DH}_{41}$ retain good binding affinity for the Manduca receptor but do not stimulate cyclic AMP production (Reagan, 1995). It is known that for many other insect neuropeptides (A-type allatostatins, kinins, FRMFamides) the active core resides in the C-terminus of the molecule (Matthew et al., 2006).

Deletion of the first 31 residues of the blattodean and orthopteran CRF-related analogues used in this study completely inhibited the peptides' ability to increase fluid secretion in mealworm tubules. In the locust, $\mathrm{Locmi}-\mathrm{DH}_{32-46}$ has very low fluid secretion activity, but remarkably, this same fragment retains biological activity in regulating satiety in locusts (Goldsworthy et al., 2003). Hence, it appears that the receptors for controlling satiety have different structure-activity requirements to the receptors in tubules (Goldsworthy et al., 2003). In the latter tissue it appears that the binding and activation regions have to be linked in the same sequence in order for the peptide to be biologically active (Coast et al., 2002).

The mealworm diuretic peptides are the only known members of the CRF-related family to have their C-termini in the non-amidated form (Furuya et al., 1995 and Furuya et al., 1998). There may be important structural requirements of the C-terminus for bioactivity, since Tenmo- $\mathrm{DH}_{37}$ had $>10000$ times lower activity than $\mathrm{Manse}^{-\mathrm{DH}_{41}}$ in elevating cyclic AMP in Manduca tubules. In the reverse assay, however, Manse- $\mathrm{DH}_{41}$ is only 17 times less potent than Tenmo-DH 37 in Tenebrio tubules (Furuya et al., 1995). Unlike the truncated analogues, the complete sequences of the locust and cockroach CRF-related 
peptides are only slightly less powerful in elevating secretion rates in mealworm tubules than Tenmo- $\mathrm{DH}_{37}$ (see Wiehart et al., 2002a), indicating a high degree of cross-reactivity in spite of the evolutionary distance between these species and the significant difference in C-terminus structure of their peptides.

\subsection{Cross-reactivity between beetle species: Effects of diuretic factors and brain homogenates}

O. gazella is a dung beetle from the family Scarabaeidae. More than 2000 species of Onthophagus have been described, making it the largest genus of beetles, and it is found on every continent except Antarctica (Emlen et al., 2005). Each stage of the life cycle is completely dependent on dung: eggs are laid in individual dung balls underground, the larva hatches inside the dung ball and remains there throughout the pupal stage until emergence as an adult beetle. Unlike tenebrionids, scarabaeids do not have a rectal complex. This structure, present in lepidopteran larvae and in some families of Coleoptera (from the superfamilies Bostrichoidia and Cucujiformia) (Saini, 1964; Lawrence and Britton, 1991), comprises the terminal portions of the Malpighian tubules, which are enclosed in a sheath around the rectum. In tenebrionids the rectal complex is capable of withdrawing water from unsaturated air, as well as from the rectal contents (Machin, 1983).

Onthophagus is only distantly related to Tenebrio and although sequence homology for CRF-related peptides is fairly low (around 50\%), with varying degrees of interspecific reactivity (Audsley et al., 1995; O'Donnell and Spring, 2000), the tubules of the dung beetle $O$. gazella appear to be very sensitive to the mealworm diuretic hormone Tenmo$\mathrm{DH}_{37}$. For this peptide in O. gazella the $\mathrm{EC}_{50}$ is $0.38 \mathrm{nM}$ while in the mealworm itself, the $\mathrm{EC}_{50}$ is $0.12 \mathrm{nM}$ and maximal stimulation (approximately $100 \%$ of maximum) is at $0.1 \mu \mathrm{M}$ (Wiehart et al., 2002a). Since CRF-related peptides appear to be ubiquitous, it is probable that $O$. gazella also makes use of a CRF-like diuretic factor similar to Tenmo$\mathrm{DH}_{37}$.

The antidiuretic effect of $O$. gazella brain homogenate was surprising, since the brains and $\mathrm{CC}$ of other beetles have previously been shown to be a source of diuretic activity. For example, homogenates from the desert tenebrionid, O. plana, produced dramatic 
increases in fluid secretion rates (Nicolson and Hanrahan, 1986). Also, the tubules of $T$. molitor are stimulated by CC extracts from Onymacris rugatipennis (Nicolson, 1992) as well as homogenates of its own brain and CC (Nicolson, 1992; Fig. 7). However, antidiuretic factors present in the brain/CC of $O$. gazella may exhibit similar effects to the mealworm antidiuretic factor Tenmo-ADFa, which inhibits fluid secretion rates in mealworm tubules and antagonises the effects of Tenmo- $\mathrm{DH}_{37}$ (Wiehart et al., 2002a). The O. gazella antidiuretic factor would thereby reverse the effects of the diuretic factor in this insect. An antidiuretic factor has been partially purified from the Colorado potato beetle (Lavigne et al., 2001), and may be related to the Tenebrio antidiuretic peptides (Coast et al., 2002).

Te Brugge et al. (2005) showed that the amount of diuretic factor (Dippu- $\left.-\mathrm{DH}_{31}\right)$ in the nervous tissue of the blood-sucking bug $R$. prolixus after feeding appeared to be diminished, indicated by reduced immunoreactivity. Following a blood meal, the diuretic factor needs to be released into circulation to precipitate diuresis. O. gazella feeds on a food source of high water content, and the beetles in this study were decapitated immediately after being removed from dung. In fact, when nervous tissue was dissected out, dung was present in the oesophagus of some of the beetles. These beetles could be releasing their diuretic hormones into circulation on a regular basis, thereby reducing the amount of stored factor in the nervous tissue.

It has been speculated that the structure of the C-terminus of Tenmo- $\mathrm{DH}_{37}$ and $-\mathrm{DH}_{47}$ might be linked to the presence of a rectal complex (Coast et al., 2002), in which case cross-reactivity between the diuretic peptides of $T$. molitor and other coleopterans possessing a rectal complex may be more pronounced. It is interesting that Tenmo- $\mathrm{DH}_{37}$, which has no effect in Manduca (possibly other insects too) does stimulate dung beetle tubules. This raises the possibility that the unusual free acid terminus of the mealworm peptides occurs elsewhere in beetles.

It is clear that there is no general pattern for the control of fluid secretion in different species, even within orders. The Malpighian tubules appear to be the target organ, but while various factors may stimulate tubules, their main function may be in other parts of the excretory system, such as the rectal complex (Audsley et al., 1993). Investigation of diuretic and antidiuretic effects in the rectal complex would prove particularly interesting. 
It needs to be stressed that while in vitro experiments are instructive, the actual physiological role of these peptides remains inconclusive and more in vivo studies are necessary to further elucidate our understanding of the function and interaction of different factors involved in beetle excretion.

\section{References}

Audsley et al., 1993 N. Audsley, G.M. Coast and D.A. Schooley, The effects of Manduca sexta diuretic hormone on fluid transport by the Malpighian tubules and cryptonephric complex of Manduca sexta, Journal of Experimental Biology 178 (1993), pp. 231-243. Audsley et al., 1995 N. Audsley, I. Kay, T.K. Hayes and G.M. Coast, Cross reactivity studies of CRF-related peptides on insect Malpighian tubules, Comparative Biochemistry and Physiology 110A (1995), pp. 87-93.

Beyenbach, 1995 K.W. Beyenbach, Mechanism and regulation of electrolyte transport in Malpighian tubules, Journal of Insect Physiology 41 (1995), pp. 197-207.

Coast, 1995 G.M. Coast, Synergism between diuretic peptides controlling ion and fluid transport in insect Malpighian tubules, Regulatory Peptides 57 (1995), pp. 283-296. Coast, 1998 G.M. Coast, Insect diuretic peptides: structures, evolution and actions, American Zoologist 38 (1998), pp. 442-449.

Coast and Kay, 1994 G.M. Coast and I. Kay, The effects of Acheta-diuretic peptide on isolated Malpighian tubules from the house cricket, Acheta domesticus, Journal of Experimental Biology 187 (1994), pp. 225-243.

Coast et al., 2001 G.M. Coast, S.G. Webster, K.M. Schegg, S.S. Tobe and D.A. Schooley, The Drosophila melanogaster homologue of an insect calcitonin-like diuretic peptide stimulates V-ATPase activity in fruit fly Malpighian tubules, Journal of Experimental Biology 204 (2001), pp. 1795-1804.

Coast et al., 2002 G.M. Coast, I. Orchard, J.E. Phillips and D.A. Schooley, Insect diuretic and antidiuretic hormones, Advances in Insect Physiology 29 (2002), pp. 279-409. Coast et al., 2005 G.M. Coast, C.S. Garside, S.G. Webster, K.M. Schegg and D.A. Schooley, Mosquito natriuretic peptide identified as a calcitonin-like diuretic hormone in Anopheles gambiae (Giles), Journal of Experimental Biology 208 (2005), pp. 3281-3291. 
Eigenheer et al., 2002 R.A. Eigenheer, S.W. Nicolson, K.M. Schegg, J.J. Hull and D.A. Schooley, Identification of a potent antidiuretic factor acting on beetle Malpighian tubules, Proceedings of the National Academy of Sciences, USA 99 (2002), pp. 84-89. Eigenheer et al., 2003 R.A. Eigenheer, U.M. Wiehart, S.W. Nicolson, L. Schoofs, K.M. Schegg, J.J. Hull and D.A. Schooley, Isolation, identification and localization of a second beetle antidiuretic peptide, Peptides 24 (2003), pp. 27-34.

Emlen et al., 2005 D.J. Emlen, J. Marangelo, B. Ball and C.W. Cunningham, Diversity in the weapons of sexual selection: horn evolution in the beetle genus Onthophagus (Coleoptera: Scarabaeidae), Evolution 59 (2005), pp. 1060-1084.

Furuya et al., 1995 K. Furuya, K.M. Schegg, H. Wang, D.S. King and D.A. Schooley, Isolation and identification of a diuretic hormone from the mealworm Tenebrio molitor, Proceedings of the National Academy of Sciences of the USA 92 (1995), pp. 1232312327.

Furuya et al., 1998 K. Furuya, K.M. Schegg and D.A. Schooley, Isolation and identification of a second diuretic hormone from Tenebrio molitor, Peptides 19 (1998), pp. 619-626.

Furuya et al., 2000 K. Furuya, R.J. Milchak, K.M. Schegg, J. Zhang, S.S. Tobe, G.M. Coast and D.A. Schooley, Cockroach diuretic hormones: characterization of a calcitoninlike peptide in insects, Proceedings of the National Academy of Sciences, USA 97 (2000), pp. 6469-6474.

Goldsworthy et al., 2003 G.J. Goldsworthy, J.S. Chung, M.S.J. Simmonds, M. Tatari, S. Varouni and C.P. Poulos, The synthesis of an analogue of the locust CRF-related diuretic peptide, and the biological activities of this and some C-terminal fragments, Peptides 24 (2003), pp. 1607-1613.

Hayes et al., 1989 T.K. Hayes, T.L. Pannabecker, D.J. Hinckley, G.M. Holman, R.J. Nachman, D.H. Petzel and K.W. Beyenbach, Leucokinins, a new family of ion transport stimulations and inhibitors in insect Malpighian tubules, Life Sciences 44 (1989), pp. $1259-1266$.

Holman et al., 1986 G.M. Holman, B.J. Cook and R.J. Nachman, Isolation, primary structure and synthesis of two neuropeptides from Leucophaea maderae: members of a 
new family of cephalomyotropins, Comparative Biochemistry and Physiology C 84 (1986), pp. 205-211.

Holman et al., 1999 G.M. Holman, R.J. Nachman and G.M. Coast, Isolation, characterization and biological activity of a diuretic myokinin neuropeptide from the housefly, Musca domestica, Peptides 20 (1999), pp. 1-10.

Holtzhausen, 2006 Holtzhausen, W.D., 2006. Diuretic factors controlling beetle Malpighian tubules: fluid secretion and immunohistochemistry. M.Sc. Thesis, University of Pretoria, South Africa.

Iaboni et al., 1998 A. Iaboni, G.M. Holman, R.J. Nachman, I. Orchard and G.M. Coast, Immunocytochemical localisation and biological activity of diuretic peptides in the housefly, Musca domestica, Cell and Tissue Research 294 (1998), pp. 549-560. Laenen, 1999 Laenen, B., 1999. Purification, characterization and mode of action of endogenous neuroendocrine factors in the forest ant, Formica polyctena. Ph.D. Thesis, Limburgs Universitair Centrum, Belgium.

Lavigne et al., 2001 C. Lavigne, J. Embleton, P. Audy, R.R. King and Y. Pelletier, Partial purification of a novel insect antidiuretic factor from the Colorado potato beetle, Leptinotarsa decemlineata (Say) (Coleoptera: Chrysomelidae), which acts on Malpighian tubules, Insect Biochemistry and Molecular Biology 31 (2001), pp. 339-347.

Lawrence and Britton, 1991 J.F. Lawrence and E.B. Britton, Coleoptera (second ed). In: D.F. Waterhouse, Editor, The Insects of Australia vol. 2, CSIRO (1991). Machin, $1983 \mathrm{~J}$. Machin, Water vapor absorption in insects, American Journal of Physiology 244 (1983), pp. R187-R192.

Matthew et al., 2006 H.J. Matthew, N. Audsley and R.J. Weaver, Alanine substitution and deletion analogues of Manduca sexta allatostatin: structure-activity relationship on the spontaneous contractions of the foregut of larval Lacanobia oleracea, Journal of Insect Physiology 52 (2006), pp. 128-135.

Nicolson, 1992 S. Nicolson, Excretory function in Tenebrio molitor: fast tubular secretion in a vapour-absorbing insect, Journal of Insect Physiology 38 (1992), pp. 139146. 
Nicolson, 1991 S.W. Nicolson, Diuresis or clearance: is there a physiological role for the "diuretic hormone" of the desert beetle Onymacris, Journal of Insect Physiology 37 (1991), pp. 447-452.

Nicolson, 1993 S.W. Nicolson, The ionic basis of fluid secretion in insect Malpighian tubules: advances in the last ten years, Journal of Insect Physiology 39 (1993), pp. 451458.

Nicolson and Hanrahan, 1986 S.W. Nicolson and S.A. Hanrahan, Diuresis in a desert beetle? Hormonal control of the Malpighian tubules of Onymacris plana (Coleoptera: Tenebrionidae), Journal of Comparative Physiology B 156 (1986), pp. 407-413.

O’Donnell and Spring, 2000 M.J. O'Donnell and J.H. Spring, Modes of control of insect Malpighian tubules: synergism, antagonism, cooperation and autonomous regulation, Journal of Insect Physiology 46 (2000), pp. 107-117.

Petzel et al., 1985 D.H. Petzel, H.H. Hagedorn and K.W. Beyenbach, Preliminary isolation of mosquito natriuretic factor, American Journal of Physiology—Regulatory, Integrative and Comparative Physiology 249 (1985), pp. R379-R386.

Reagan, 1995 J.D. Reagan, Functional expression of a diuretic hormone receptor in Baculovirus-infected insect cells: evidence suggesting that the $\mathrm{N}$-terminal region of diuretic hormone is associated with receptor activation, Insect Biochemistry and Molecular Biology 25 (1995), pp. 535-539.

Saini, 1964 R.S. Saini, Histology and physiology of the crytonephridial system of insects, Transactions of the Entomological Society of London 116 (1964), pp. 347-392.

Te Brugge et al., 2005 V.A. Te Brugge, V.C. Lombardi, D.A. Schooley and I. Orchard, Presence and activity of a Dippu- $\mathrm{DH}_{31}$-like peptide in the blood-feeding bug, Rhodnius prolixus, Peptides 26 (2005), pp. 29-42.

Thastrup et al., 1990 O. Thastrup, P.J. Cullen, B.K. Drøbak, M.R. Hanley and A.P. Dawson, Thapsigargin discharges intracellular $\mathrm{Ca}^{2+}$ stores by specific inhibition of the endoplasmic reticulum $\mathrm{Ca}^{2(+)}$-ATPase, Proceedings of the National Academy of Sciences, USA 87 (1990), pp. 2466-2470.

Wiehart et al., 2002a U.I.M. Wiehart, S.W. Nicolson, R.A. Eigenheer and D.A. Schooley, Antagonistic control of fluid secretion by the Malpighian tubules of Tenebrio molitor: 
effects of diuretic and antidiuretic peptides and their second messengers, Journal of Experimental Biology 205 (2002), pp. 493-501.

Wiehart et al., 2002b U.I.M. Wiehart, P. Torfs, A. Van Lommel, S.W. Nicolson and L. Schoofs, Immunocytochemical localisation of a diuretic hormone of the beetle Tenebrio molitor, Tenmo-- $\mathrm{DH}_{37}$, in the nervous system and midgut, Cell and Tissue Research 308 (2002), pp. 421-429.

Yu and Beyenbach, 2002 M-J. Yu and K.W. Beyenbach, Leucokinin activates $\mathrm{Ca}^{2+}$ dependent signal pathway in principal cells of Aedes aegypti Malpighian tubules, American Journal of Physiology—Renal Physiology 283 (2002), pp. F499-F508.

Corresponding author. Tel.: +27 12420 3233; fax: +27 123625242 . 